\title{
Percepção da enfermagem no cuidar às mulheres em processo de abortamento em hospital de referência no interior da Bahia
}

\author{
Magno Conceição das Merces*, Juliana Bahia Rigaud**, Caroline da Silva Barbosa**, \\ Bárbara Emyle Ramos Borges**, Liliane Souza Lopes**, André Henrique do Vale de Almeida, M.Sc.***, \\ Maria Lúcia Silva Servo, D.Sc.****
}

*Biólogo Sanitarista, Enfermeiro, Professor Auxiliar do Curso de Enfermagem da Universidade do Estado da Bahia,

${ }^{*}$ Enfermeira da Prefeitura Municipal de Feira de Santana ${ }^{* *}$ Enfermeiro, Mestre em Saúde Coletiva pela Universidade

Estadual de Feira de Santana/BA, ****Enfermeira, Professora Plena da Universidade Estadual de Feira de Santana

\begin{abstract}
Resumo
O aborto no Brasil constitui-se em problema de saúde pública que traz consequências negativas para as mulheres que o praticam e colabora para a propagação da desigualdade social. As mulheres de classes sociais menos favorecidas são as que mais sofrem, pois não têm acesso à assistência médica para a realizaçáo de um procedimento seguro. Trata-se de um estudo qualitativo, descritivo e exploratório, que teve como objetivo analisar a percepçáo da equipe de enfermagem no cuidar de mulheres em processo de abortamento que atua no Hospital Inácia dos Santos em Feira de Santana - BA. Os dados foram obtidos através de uma entrevista semiestruturada com 22 profissionais da equipe de enfermagem do centro obstétrico. Após a análise criteriosa dos dados, através da técnica de análise de conteúdo de Bardin, o estudo apontou três categorias, que são: o olhar dos profissionais de enfermagem sobre o processo de abortamento; influência dos valores morais na assistência às mulheres em processo de abortamento e a humanização da equipe de enfermagem no processo de abortamento. $\mathrm{O}$ estudo sinaliza que a percepçáo da equipe de enfermagem no cuidar de mulheres em processo de abortamento perpassa pela resistência na abordagem do profissional da equipe de enfermagem à mulher, que é uma das formas mais eficazes de acolhimento e humanização.
\end{abstract}

Palavras-chave: mulher, aborto, equipe de enfermagem, humanização da assistência.

\section{Abstract \\ Perception of nursing team in caring for women undergoing abortion process in a reference hospital of Bahia}

Abortion in Brazil is a public health problem that has negative effects on women and contributes to spread social inequality. Women from lower social classes are the most affected, as they do not have access to appropriate health care services to have a safe abortion procedure. This is a qualitative, descriptive and exploratory study, which aims at analyzing the perception of nursing team in caring for women who were in process of abortion in Hospital Inácia dos Santos Hospital 
in Feira de Santana - BA. Data were obtained through semi-structured interviews with 22 professionals of nursing team in the obstetric ward. After careful analysis of data, using the technique of content analysis proposed by Bardin, the study identified three categories, as follows: the position of nursing professionals on the abortion process; influence of moral values in caring for women undergoing abortion and humanization of nursing team during abortion process. The study points out that the perception of the nursing team in caring for women undergoing abortion pervades the resistance of professional nursing team to approach the woman, which is one of the most effective ways to be well received and more humane.

Key-words: woman, abortion, nursing team, humanization of assistance.

\section{Resumen}

\section{Percepción de la atención de enfermería para las mujeres en el proceso de aborto en un hospital de referencia en Bahia}

El aborto en Brasil es un problema de salud que trae consecuencias negativas para las mujeres que se lo practican y colabora para la propagación de la desigualdad social. Las mujeres de clases sociales menos favorecidas son las que más sufren, pues no tienen acceso a la asistencia médica para la realización de un procedimiento seguro. Se trata de un estudio cualitativo, descriptivo y exploratorio que tuvo como objetivo analizar la percepción del equipo de enfermería en la atención a mujeres en proceso de aborto en el Hospital Municipal Inácia Pinto dos Santos de Feira de Santana-BA. Los datos fueron obtenidos a través de entrevista semiestructurada con 22 profesionales del equipo de enfermería del centro obstétrico. Después de realizar un análisis de los datos con criterio, a través de la técnica de análisis de contenido de Bardin, el estudio apuntó tres categorías: la opinión del profesional de enfermería sobre el proceso de aborto; influencia de los valores morales en la asistencia a mujeres en proceso de aborto y la humanización del equipo de enfermería en el proceso de aborto. El estudio apunta que la percepción del equipo de enfermería en la atención a mujeres en proceso de aborto ultrapasa la resistencia del profesional del equipo de enfermería para abordar la mujer, que es una de las formas más eficaces de acogida y humanización.

Palabras-clave: mujer, aborto, grupo de enfermería, humanización de la atención.

\section{Introdução}

A inviolabilidade que rege a Constituição Federal do Brasil quando trata do direito à vida é justificada pelas diferentes concepçôes sobre seu início. Algumas teorias afirmam que há vida no momento em que o espermatozóide fecunda o óvulo, outras só depois que o coraçáo começa a pulsar e ainda há quem acredite que a vida só se faz presente depois do início das funçóes cerebrais. A existência de um leque de teorias justifica a ilegalidade do aborto frente à sociedade, ao Estado e à igreja, já que o mesmo é considerado assassinato [1].

A ilegalidade do aborto traz consequências negativas para as mulheres que o praticam, não impede sua prática e ainda colabora para a propagação da desigualdade social. As mulheres de classes sociais menos favorecidas são as que mais sofrem, pois não têm acesso à assistência médica para a realização de um procedimento seguro. No Brasil, o aborto é considerado "questão de saúde pública" e, desta forma, deve ser entendido não como um ato imoral de mulheres levianas, mas como um fenômeno que precisa ser levado a sério, respeitando os direitos humanos [2].

Assim, há uma grande necessidade de aperfeiçoar o atendimento prestado a essas mulheres, não apenas no aspecto técnico do cuidar, mas também no acolhimento, fazendo com que este seja prestado de forma humanizada. Considerando que a humanização é o processo chave para uma assistência qualificada, é mister uma abordagem eficaz por parte da equipe de enfermagem, proporcionando assim o bem estar físico e emocional à paciente.

A humanização para muitos está relacionada a um ambiente adequado, permissão de familiares próximos ao cliente, conforto e privacidade [3]. Entretanto, para que a humanização seja implementada 
é relevante não apenas o ambiente físico adequado, mas também uma conduta adequada e comprometida no relacionamento interpessoal entre os atores sociais envolvidos, valorizando a comunicação entre profissional e cliente [4].

Deste modo, analisar a percepção da equipe de enfermagem no cuidado às mulheres em processo de abortamento nos possibilitará identificar a presença da humanização na assistência que é prestada.

O presente estudo objetiva analisar a percepção da equipe de enfermagem no cuidar de mulheres em processo de abortamento no Centro Obstétrico do Hospital Municipal Inácia Pinto dos Santos de Feira de Santana-BA.

\section{Material e métodos}

Trata-se de um estudo qualitativo, exploratório e descritivo, realizado com 22 profissionais da equipe de enfermagem do centro obstétrico (7 enfermeiros e 15 técnicos de enfermagem) do Hospital Municipal Inácia Pinto dos Santos de Feira de Santana-BA em 2011. Os critérios de inclusão dos sujeitos na pesquisa foram: estarem em pleno exercício profissional no desenvolvimento de atividades de assistência direta às mulheres em processo de abortamento e que concordassem em participar voluntariamente da investigação. A coleta de dados foi iniciada após a aprovação da pesquisa pelo Comitê de Ética da Faculdade Adventista da Bahia, sob parecer de $\mathrm{n}^{\circ} 015 / 11$. Utilizou-se a entrevista semiestruturada para a coleta de dados, onde foi solicitada a assinatura do Termo de Consentimento Livre e Esclarecido. Para análise dos dados, optou-se pela técnica de análise de conteúdo de Bardin. Após análise criteriosa dos dados, envolvendo a escuta e transcrição das entrevistas, observando os núcleos de sentido, as semelhanças e divergências dos discursos dos sujeitos, foram apreendidas as categorias, a seguir: o olhar dos profissionais de enfermagem sobre o processo de abortamento; influência dos valores morais na assistência às mulheres em processo de abortamento e a humanização da equipe de enfermagem no processo de abortamento.

Esta pesquisa obedeceu aos princípios éticos de forma a garantir o sigilo das informaçóes sobre os sujeitos da pesquisa, obedecendo à resoluçáo 196/96 do Conselho Nacional de Saúde. Além disso, asseguramos a privacidade dos sujeitos, de forma a respeitar a integralidade moral, intelectual, social e cultural dos envolvidos.

\section{Resultados e discussão}

O estudo aponta que os sujeitos participantes do estudo encontram-se na religião católica (12), na religião evangélica (3) e sem religiôes definidas (7). As igrejas, tanto católica quanto evangélicas, acreditam que após a fecundação a vida já está presente, devido a esse preceito, condenam a prática do aborto e o consideram como assassinato. A pesquisa nos mostrou que (15) dos sujeitos do estudo, pertencentes a essas crenças, são maleáveis em relação ao aborto, a depender da situação, posicionando-se contra ou a favor da prática do aborto, após avaliar a situação em que a mulher está inserida, como podemos observar nas falas abaixo:

\footnotetext{
"Poxa... mas eu penso numa mulher que é solteira, o cara não assume... e aí? Me coloco no lugar dela, e mesmo achando errado matar a criança, é uma situação muito delicada”.(P.10)

"Só sou a favor quando é estupro".

A seguir, apresentamos, analisamos e discuti-
} mos as categorias apreendidas no estudo.

\section{O olhar dos profissionais de enfermagem sobre o processo de abortamento}

Os valores culturais e sociais têm influenciado o olhar que muitos profissionais têm em relação às mulheres que abortam, levando-os a considerar que elas praticam este ato devido ao desespero familiar, omissão ou ausência de um companheiro, condiçôes financeiras e planejamento familiar ineficaz ou inadequado. Grande parcela de mulheres consegue ter fácil acesso a métodos abortivos por indicação de conhecidos, ou não, o que acaba gerando situaçóes de risco de vida, contudo, esta prática é considerada como um pecado pelos trabalhadores e sendo assim deve ser realizada somente em caso de estupro.

Os profissionais de enfermagem do Centro Obstétrico do Hospital Municipal Inácia Pinto dos Santos, em Feira de Santana, ficaram divididos sobre o que induz uma mulher a praticar o aborto. A maioria (15) refere que a situação deve ser levada em consideração, onde determinados acontecimentos podem justificar sua prática, outros (5) se colocam como contra e (2) são a favor. 
O olhar dos profissionais de enfermagem sobre o direito de interromper a gravidez se opóe a concepçáo de aborto como sendo um pecado. A ideia do aborto como um direito de escolha, um direito da mulher, identifica-se com os discursos do universo feminista, que o vê como um direito reprodutivo da mulher. Por outro lado, o fato da mulher haver sofrido violência sexual e vir por esta a engravidar, decidindo-se pelo abortamento foi um argumento que suavizou ou de certa forma eximiu da responsabilidade o profissional de saúde.

A perda de um filho configura um tipo peculiar de luto, que de alguma maneira envolve culpa e revolta, independente do meio através do qual este veio a falecer. O aborto acaba por "mexer" com os sentimentos das gestantes, alterando tanto a sua relação consigo mesma quanto as relaçôes dentro do sistema familiar.

De acordo com Gesteira [5], mesmo diante de todas as dificuldades e desafios enfrentadas pelos profissionais de saúde, no cuidar de mulheres violentadas, tratar de violência tem mais aceitação do que discutir a interrupção da gravidez.

Muitos profissionais, como afirma Soares [6], fazem referência ao fato de estarem atendendo a uma determinaçáo superior e asseguram sentirem-se protegidos por haver amparo legal para o atendimento de mulheres em processo de aborto; fato comprovado no decorrer desta pesquisa, através dos discursos dos entrevistados.

Ao indagarem às mulheres sobre o que causou o aborto, se este foi espontâneo ou provocado, os profissionais entrevistados referiram que nem sempre as mulheres respondem verdadeiramente o que o causou. A possibilidade de ser julgada ou condenada por um ato que não é considerado legal faz com que elas neguem. Para os profissionais de enfermagem, as mulheres preferem livrar-se da gravidez praticando o aborto do que se informar das consequências do mesmo. Muitas delas chegam com lesóes extremamente graves e depois ficam sabendo que não podem mais ter filhos, expressando assim arrependimento e culpa.

Alguns profissionais afirmaram ser importante questionar as mulheres em processo de abortamento sobre a causa do aborto, enquanto que a minoria não acha necessário este questionamento, o que pode ocasionar condutas inadequadas no cuidado prestado às mesmas. Ressaltaram ainda a importância da abordagem sugestiva, uma vez que a paciente em processo de abortamento nem sempre confirma a indução planejada do aborto. Em alguns casos náo se é possível determinar se o abortamento foi espontâneo ou provocado.

No entanto, um pré-julgamento ainda que superficial e aparentemente inocente é percebido ao se diferenciar as ideias de gravidez desejada e indesejada. Para alguns profissionais, quando a paciente apresenta um aborto com características de espontâneo, esta se mostra ainda mais fragilizada, merecendo entáo um suporte médico e emocional mais abrangente. Em contrapartida, aquelas que confessam ou que trazem indícios de um aborto induzido, recebem informaçóes sobre os riscos e consequências de se interromper uma gravidez, considerada neste caso como indesejada.

O abortamento provocado tem sido apontado como consequência do desconhecimento ou náo do acesso da mulher aos métodos anticoncepcionais, a falta de uma educação sexual e a paternidade sem maiores responsabilidades, sofrendo ainda o acréscimo da falta de tecnologia contraceptiva dos serviços básicos de saúde. Diante de todos esses aspectos temos uma gestante sem maiores esperanças, sentindo-se destinada a enfrentar uma gravidez indesejada. Todo o andamento desde a detecçáo da gravidez até o momento final da decisão de interrompê-la acarreta na gestante um período de descontrole emocional e sensibilidade exacerbada. Por este motivo, alguns autores como Burroughs [7] afirmam que a mulher que enfrenta esse processo deve receber a mesma atenção e assistência daquela que se encontra no período do puerpério.

Em todos os casos, a preocupação de toda equipe de saúde é de não diferenciar o tratamento oferecido, buscando diagnosticar a etiologia do processo abortivo, cuidando para náo julgar as suas causas. Toda uma sensibilização é feita para que esta paciente náo volte a cometer o mesmo ato, buscando assim proteger ainda que indiretamente a saúde da mulher.

Embora o abortamento seja um procedimento obstétrico comum, este jamais deve ser encarado pela equipe de Enfermagem como rotineiro. Neste sentido, o profissional náo pode deixar-se conduzir pelo caminho do mecanismo, tratando para isso cada caso como um em especial, uma vez que o sentimento de culpa, incapacidade e fracasso fatalmente acometerá cada paciente, independente do processo abortivo ser espontâneo ou por ela mesma provocado [7]. 


\section{A influência dos valores morais na assistência às mulheres em processo de abortamento}

Os profissionais de enfermagem que não possuem qualificação eficaz para lidar com as mulheres em processo de abortamento colaboram para a manutenção de atitudes de julgamento de valores e preconceitos que podem interferir no atendimento. Deste modo, a humanizaçáo e o acolhimento necessários para prestar um atendimento digno e respeitoso a estas mulheres, muitas vezes são deixados de lado.

O que pode-se perceber nesta pesquisa é que a maioria dos profissionais de enfermagem deixa os seus valores morais interferirem na assistência a estas mulheres em processo de abortamento. Este resultado nos leva a sinalizar que os valores morais são de grande relevância na assistência às mulheres em processo de abortamento como podemos observar em algumas falas abaixo dos profissionais que foram entrevistados:

"A assistência de enfermagem sofre influência de valores morais infelizmente, pois na maioria das vezes colocamos nossos propósitos de vida como objetivos do outro." (P.5)

\footnotetext{
"Nós seres humanos não estamos acostumados a lidar com tais fatos com naturalidade, $\mathrm{e}$ às vezes restringimos o cuidado fazendo com que o atendimento seja ineficaz". (P.9)

"Por questôes religiosas ou valores morais os profissionais de saúde muitas vezes agem com discriminação ao prestar assistência à mulher em processo de abortamento.” (P.21)
}

Moldando-se pelos valores morais vigentes, que persistem em diversos contextos políticos, há uma resistência à implantação do aborto previsto em lei e as problemáticas resultantes da violência sexual nos estados brasileiros. Um dos empecilhos para a implantaçáo dos serviços de atendimento ao aborto previsto por lei tem sido a disponibilidade de profissionais de saúde para atuar nesse contexto [8].

Ainda segundo Soares [8], a proteção às mulheres vítimas de violência sexual, como uma afirmativa de saúde, trouxe para a realidade dos serviços, temáticas como o aborto, a violência sexual e doméstica e as relaçóes de gênero que se apresentam de difícil compreensão para os profissionais. Em meio a outras razóes, a resistência para lidar com estas questóes esteve atribuída à falta de capacitação e domínio teórico e prático dos problemas resultantes da violência sexual, já que essa temática não se apresenta como uma parte obrigatória da formação acadêmica dos profissionais de saúde. Normalmente, a assistência prestada por esses profissionais é orientada pela concepção que a prática abortiva é crime, sem fazer alusão aos direitos reprodutivos ou às questóes sociais que derivam da problemática da clandestinidade.

\section{A humanizaçáo da equipe de enfermagem no processo de abortamento}

A Humanização da assistência é tema muito discutido em vários momentos na formação do profissional enfermeiro, porém é de grande relevância avaliar sua prática no cotidiano e em diferentes situaçóes. Esse questionamento visou avaliar a humanização que é praticada em um setor de grande rotatividade de pacientes e que ainda atende mulheres que provocam o aborto. Nesse momento, nosso objetivo foi avaliar o conhecimento da equipe de enfermagem sobre a humanização e se ela é diferenciada a depender da causa do internamento da paciente.

Os sujeitos do estudo referem que a humanização na assistência às mulheres em processo de abortamento está ausente desde a primeira abordagem até a finalização do procedimento, em contra partida, a minoria acredita que a humanizaçáo está inserida na assistência.

Os fragmentos de discursos a seguir retratam as afirmativas sobre a humanização na assistência a esse grupo de mulheres:

"Com certeza está, e devemos sim, sempre agir com muito profissionalismo e não devemos de forma alguma negligenciar a assistência a alguém por conta da nossa opiniáo em determinados aspectos”. (P.12)

\footnotetext{
"Sim, mesmo porque não justifica que o aborto seja algo monstruoso para náo dar o apoio a cliente, cada um sabe seus motivos de levá-la a cometer esse ato, além do que temos que prestar assistência humanizada para qualquer mulher e não ficar julgando". (P.4)

“Infelizmente não. Encontramos $70 \%$ de profissionais interessados em apenas realizar
} 
o procedimento, ou em outros casos, apontar o erro que a cliente fez". (P.7)

"A humanização deveria estar inserida no processo de abortamento, o que na maioria das vezes não acontece. A equipe acaba imprimindo valores pessoais na sua assistência, que na verdade deveria ser imparcial e humanizada”. (P.14)

"Não. Nos preocupamos em realizar somente o procedimento. Quando tentamos nos relacionar mais com a cliente e essa demonstra que o aborto foi escolha dela, envolvemos nossos valores e princípios, julgando assim a atitude desta mulher, podendo até interferir a qualidade da assistência que ela vai receber". (P.22)

No ano de 2000, o Ministério da Saúde implantou a Política Nacional de Humanização, afirmando: "[...] atender às demandas subjetivas manifestadas pelos usuários e trabalhadores dos serviços de saúde, baseando-se na integralidade da assistência. Nesse sentindo, a Política Nacional de Atenção Integral à Saúde da Mulher (PAISM) destaca-se com o objetivo de qualificar e humanizar a assistência às mulheres em situação de abortamento" [8].

Com a prática da humanizaçáo no atendimento às mulheres em processo de abortamento a qualidade do serviço aumenta, o que faz com que o atendimento seja composto de uma assistência holística à mulher, atentando não apenas para a realização de técnicas, mas visando o bem estar físico e psicológico. Desta forma, o cuidado prestado está em concordância com o princípio da integralidade, preconizado pelo SUS, além de contemplar a equidade, pois, os profissionais estarão oferecendo maior atenção onde há maior necessidade de acolhimento psicológico. Ocorre assim uma valorização da dignidade tanto do profissional quanto do paciente.

\section{Conclusão}

Este estudo oportunizou estar próximo dos profissionais de enfermagem que prestam cuidados diretos às mulheres que provocam o aborto, o que possibilitou observar as reaçóes, percepçóes e sentimentos através do questionário que foi aplicado a esses profissionais. Buscou-se apreender o explícito e o implícito no conteúdo dos depoimentos, proporcionando momentos de trocas, as quais foram produtivas e ajudaram a compreender a forma como eles vivenciam o cuidado a mulheres em processo de abortamento.

Diante de todos os fatos relatados e a análise dos resultados, podemos inferir que a visão dos profissionais de saúde envolvidos na assistência às mulheres em processo de abortamento sinalizou inúmeros desafios na assistência de enfermagem com presença de elementos como a hierarquia do trabalho de saúde, os conflitos internos existentes, a influência religiosa, o comprometimento com a assistência e a humanização do serviço.

A visão dinâmica dos resultados possibilitou a expressáo das várias significaçóes colocadas em campos opostos e por isso conflitantes, que muitas vezes coexistiram na mesma pessoa. As representaçóes romperam a visão unilateral e trouxeram à tona a relação entre valores e significados. As dimensóes técnicas, legais e éticas explicam os motivos que levaram a adesão dos profissionais na assistência a estas mulheres, percebendo-se que ao mesmo tempo em que acreditam estar fazendo algo correto técnica e eticamente, compartilham de uma fonte cultural que coloca o abortamento como uma questáo moral e religiosa.

A equipe de enfermagem é responsável por oferecer um atendimento às mulheres em processo de abortamento de qualidade, afastado de preconceitos ligados a valores morais, religiosos e culturais com responsabilidade e ética. A ética que rege as profissóes da saúde está presente no processo de cuidar, incluindo respeito aos direitos do ser humano, à vida, à dignidade em todo o ciclo vital, sem discriminação.

A relevância desta pesquisa é centrada na possibilidade de despertar nos profissionais da saúde e estudantes em formação, reflexôes sobre o cuidado, que vão além do conhecimento científico e de procedimentos técnicos, envolvendo percepçôes, sentimentos, ética, dentre outros. No que diz respeito, especificamente, à equipe de enfermagem, os resultados dessa investigação podem ampliar conhecimentos e favorecer o cuidado, por meio de um planejamento adequado, incluindo a sistematização da assistência de enfermagem.

Construir essa pesquisa se constituiu em um grande desafio, pois a abordagem de um tema polêmico como o abortamento provocou várias inquietaçóes, principalmente relacionadas à aceitação 
dos profissionais em participar da pesquisa, aliado ao acompanhamento dos pesquisadores durante a permanência no ambiente hospitalar.

\section{Referências}

1. Szklarz E. Quando começa a vida? Revista Super. São Paulo: Abril; 2007, n. 240 A.

2. Brasil. Ministério da Saúde. Secretaria de Ciência, Tecnologia e Insumos Estratégicos. Departamento de Ciência e Tecnologia. Aborto e Saúde Pública: 20 anos de pesquisa no Brasil. Brasília: Ministério da Saúde; 2008.

3. Albuquerque NMG. Vivência do enfermeiro no cuidado humano na unidade de terapia intensiva adulto [Dissertação]. Natal: Universidade Federal do Rio Grande do Norte; 2007.
4. Backes SD, Martins D, Dellazzana AR. É possível humanizar o cuidado no CTI? In: Costenaro RGS, ed. Cuidando em enfermagem: pesquisas e reflexóes. Santa Maria: Centro Universitário Franciscano; 2001. p. 35-52.

5. Gesteira SMA, Diniz NMF, Oliveira EM. Assistência à mulher em processo de abortamento provocado: discurso de profissionais de enfermagem. Acta Paul Enferm 2008;21(3):449-53.

6. Soares GS. Profissionais de saúde frente ao aborto legal no Brasil: desafios, conflitos e significados. Cad Saúde Pública 2003;19(2):399-406.

7. Burroughs A. Uma introdução à enfermagem materna. 6a ed. Porto Alegre: Artes Médicas; 1995.

8. Brasil. Ministério da Saúde. Secretaria de Atenção à Saúde. Departamento de Açôes Programáticas Estratégicas. Política Nacional de Atenção Integral à Saúde da Mulher: Princípios e Diretrizes. Brasília: Ministério da Saúde; 2004. 